\title{
Does maternal dietary mineral restriction per se predispose the offspring to insulin resistance?
}

\author{
Lagishetty Venu, Nemani Harishankar ${ }^{1}$, Tripuraribhatla Prasanna Krishna ${ }^{2}$ and Manchala Raghunath \\ Divisions of Endocrinology and Metabolism and ${ }^{2}$ Statistics and ${ }^{1}$ National Centre for Laboratory Animal Sciences, National Institute of Nutrition (ICMR), \\ Hyderabad-500 007, India
}

(Correspondence should be addressed to M Raghunath, Division of Endocrinology and Metabolism, National Institute of Nutrition (ICMR), Jamai Osmania P O Hyderabad-500 007, India; Email: manchalar@yahoo.com)

\begin{abstract}
Background: Maternal undernutrition is hypothesized to predispose the offspring to disease in adult life. The relevance of maternal macronutrient deficiency has been well studied but not that of micronutrients.

Objective: To assess the effect of maternal dietary mineral restriction per se on oral glucose tolerance (OGT), insulin resistance (IR) and fat metabolism in offspring.

Design: Female weanling Wistar/NIN rats received a control or a $50 \%$ mineral-restricted (MR) diet for 12 weeks, by which time MR rats had lower plasma $\mathrm{Fe}, \mathrm{Zn}, \mathrm{Mg}$ and Ca concentrations. Following mating with control males, a third of the MR dams were shifted to the control diet from parturition. Half of the pups born to the remaining MR dams were weaned onto the control diet while the other half continued on the MR diet.

Results: Pregnant MR dams had a higher abortion rate, body weights of their pups at birth and weaning were lower and rehabilitation had no beneficial effect. No offspring had impaired OGT, and IR status was comparable among different groups on postnatal days 40, 70, 100 or 180. Compared with controls, total body electrical conductivity measurements indicated significantly higher body fat \%, lower lean body mass and fat-free mass in MR offspring besides elevated plasma triacylglycerols. Mineral rehabilitation from parturition or weaning had little effect on these changes, which did not appear to be due to increased oxidative stress.

Conclusions: Maternal MR per se resulted in an increase in body fat and in plasma triacylglycerol concentrations in the offspring. These changes had, however, no discernable effect on insulin sensitivity over the first 180 days of life.
\end{abstract}

European Journal of Endocrinology $151287-294$

\section{Introduction}

Exposure of the fetus to maternal malnutrition is a wellknown causal factor for intrauterine growth retardation, both in humans and other animals $(1,2)$. Abundant epidemiological evidence in humans has shown an association between coronary heart disease, hypertension, non-insulin-dependent diabetes and impaired glucose tolerance in adults on the one hand, and low birth weight and altered fetal growth on the other $(3-5)$. Elevated blood pressure, glucose intolerance and dyslipidaemia occur together frequently in humans and are collectively termed as the "metabolic syndrome' $(6,7)$. The fetal origin of adult disease hypothesis proposes that these disorders derive from fetal adaptations in utero to maternal undernutrition, which permanently alters growth characteristics and postnatal metabolism and physiology $(8,9)$. Indeed, a number of animal models have been established to try to understand the mechanistic basis of this relationship $(10,11)$, but most of them considered only the maternal deficiency of macronutrients. For example, maternal dietary restrictions of calories (12) and protein (13), and umbilical artery ligation (14) have all been shown to cause fetal growth retardation, alter fat and glucose metabolism and elevate blood pressure in the offspring. The data from these studies suggest that poor maternal nutrition during pregnancy may lead to metabolic and morphological changes in the fetus, with lifelong consequences.

It is well recognized that micronutrients, especially the minerals, play an important role in the structural and metabolic activities of the organism. For example, zinc, magnesium, manganese, iron and copper are known to modulate the synthesis, storage, release and conformational integrity of insulin (15). Chromium increases insulin binding due to an increase in insulin receptor number, activation of insulin receptor kinases and inhibition of insulin receptor phosphatases (16). Vanadium shows insulin mimetic effects in vivo and in vitro when used in pharmacologic doses (17). Recently, dietary iron restriction in rat dams has been shown to 
increase hypertension and alter lipid metabolism in the offspring (18).

Moreover, mineral deficiencies and anemia are common in the developing world, particularly during pregnancy and lactation (19). It is also known that maternal mineral deficiencies are associated with low birth weight and increased rates of perinatal mortality and morbidity (20). Further, in developing countries, the prevalence of low birth weight varies from 13\% to $30 \%(21)$. Despite this and the known effects of minerals per se on insulin synthesis/release/action, the role of maternal mineral deficiencies in the etiology of insulin resistance in the offspring has not yet been explored.

In view of previous studies, we hypothesized that maternal dietary mineral restriction per se predisposes the offspring to insulin resistance in later life. The present study was conducted in albino rats to validate/ negate this hypothesis.

\section{Materials and methods}

\section{Animals: feeding, maintenance and breeding}

The animal experimental protocol and all the procedures involved were approved by the National Institute of Nutrition ethical committee on animal experiments.

Twenty, female, weaning Wistar/NIN (WNIN) rats were obtained from the National Centre for Laboratory Animal Sciences, National Institute of Nutrition, Hyderabad, India. They were housed individually in polypropylene cages with wire mesh bottom and maintained at $22 \pm 2{ }^{\circ} \mathrm{C}$ under standard lighting conditions (12 h light: $12 \mathrm{~h}$ darkness). Of these, 14 were fed for 12 weeks on a control diet (based on the American Institute of Nutrition AIN-93G diet) (22) with 50\% restriction of mineral mixture and they were provided with deionized water. The remaining six animals were pairfed with six rats fed the mineral-restricted (MR) diet. At the end of 12 weeks of feeding, blood was collected from the supra-orbital sinus for determining the concentrations of iron, zinc, copper, magnesium and calcium in plasma, in addition to the following biochemical parameters: haemoglobin, glucose, insulin, cholesterol and triacylglycerols.

After assessing their mineral status, the rats were mated with control males and maintained on their respective diets throughout gestation. At parturition, one-third of the MR dams $(n=4)$ were shifted to control diets (MSP) and the remaining two-thirds of the dams continued on restricted diets throughout lactation. A uniform litter size was maintained in all groups by adjusting the number of offspring per litter to eight on postnatal day 3. At 21 days of age (weaning), half of the pups born to MR mothers were weaned onto the control diet (MSW) and the remaining half continued on restricted diets (MR). From weaning onwards, in each group eight male pups were maintained until postnatal day 180. The feeding protocol used in this experiment is depicted schematically in Fig. 1.

Diet intake and body weights were recorded daily and weekly respectively in both mothers and offspring. At the end of 100 and 180 days of feeding of the offspring, body length was measured as the length between the tip of nose and the centre of the anus. Body mass index (BMI) was calculated from the formula: $\mathrm{BMI}=$ body weight in $\mathrm{kg} /$ body length in $\mathrm{m}^{2}$.

\section{Oral glucose-tolerance test}

An oral glucose-tolerance test (OGTT) was performed in the offspring on postnatal days 40, 70, 100 and 180 . After an overnight fast, glucose $(300 \mathrm{gm} / \mathrm{l})$ was administered orogastrically at a dose of $2.5 \mathrm{~g} / \mathrm{kg}$ body weight and blood samples were obtained from the orbital sinus at 0,60 and $120 \mathrm{~min}$ for determination of plasma glucose and insulin concentrations. The glucose and insulin responses during the OGTT were calculated by estimation of the total area under curves (AUC) for glucose and insulin respectively, using the trapezoidal method (23).

\section{Physiological indices of insulin resistance/glucose tolerance}

Indices based on fasting glucose and insulin concentrations (homeostasis model of assessment of insulin resistance (HOMA-IR)) as well as those which take into account the response to a challenge with oral glucose (glucose AUC/insulin AUC) were computed as follows. (i) HOMA-IR: insulin resistance was assessed from fasting glucose and fasting insulin concentrations as follows: HOMA IR $=($ fasting insulin $(\mu \mathrm{U} / \mathrm{ml}) \times$ fasting glucose $(\mathrm{mM})) / 22.5$ and (ii) ratio of glucose AUC to insulin AUC: AUC for glucose and insulin during the OGTT

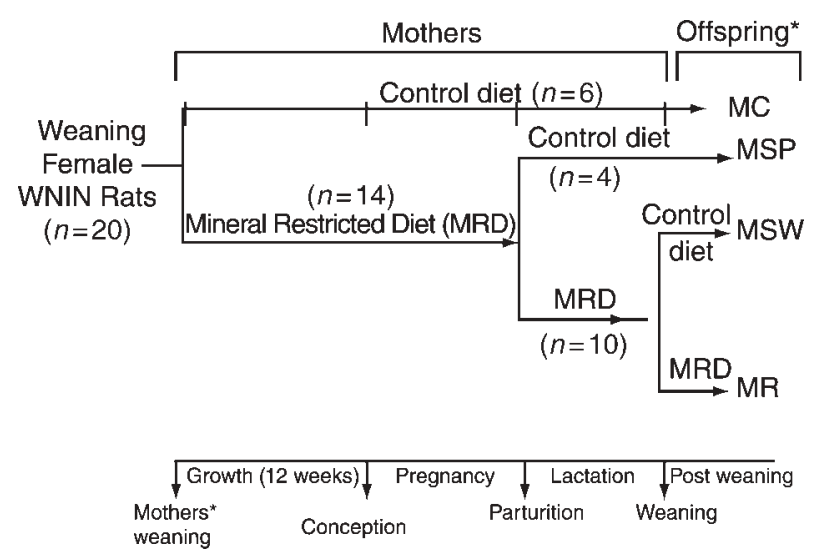

Figure 1 Schematic representation of the feeding protocol of different groups of mothers and offspring. ${ }^{*} n=8$ offspring in each group from weaning. 
were calculated by the trzapezoidal method (23) and the ratio of glucose AUC/insulin AUC was computed.

\section{Measurements in plasma}

Blood was collected from offspring at 40, 70, 100 and 180 days of age following an overnight fast; plasma was separated and stored at $-20^{\circ} \mathrm{C}$ until analysis. Iron, zinc, copper, magnesium and calcium concentrations were measured in maternal plasma by atomic absorption spectroscopy (Varian spectrAA 220) (24).

Plasma glucose and high density lipoprotein (HDL) cholesterol levels were measured enzymatically using commercially available kits (Dr Reddy Laboratories, Hyderabad, India) according to the manufacturer's instructions. Total cholesterol and triacylglycerols were measured in fasting plasma using commercially available kits from Biosystems, Barcelona, Spain. Plasma insulin was measured using a radioimmunoassay kit from BRIT, Mumbai, India.

\section{Body composition of the offspring}

Total body composition of the offspring was determined at 100 and 180 days of age using a total body electrical conductivity (TOBEC) small animal body composition analysis system (EM-SCAN, Model SA-3000 multi detector, Springfield, IL, USA) $(25,26)$. The difference between the impedance measured when the animal is inside the electromagnetic field and when the chamber is empty is an index of the total electrical conductivity (E) of the body which, in turn, is proportional to the animal's lean body mass (LBM).

Prior to TOBEC measurement, the rats were anesthetized lightly with ether and placed in a carrier in such a way that the animal's body was stretched to its maximum comfortable length. Then the carrier was placed in the TOBEC chamber and 10-12 recordings/scans were taken from each rat. The highest and lowest readings were excluded and the remaining ten were averaged. The intra-assay coefficient of variation was less than $3.0 \%$. Prior to the in vivo measurement, the instrument was calibrated with a standard coil (ID 3076) supplied with the instrument and the empty chamber read 0-2 units.

The following body composition parameters were obtained mathematically according to the methods of Morbach et al. (27). (i) $\mathrm{LBM}=0.5 \mathrm{E}+(0.3 \times$ total body weight); (ii) total body fat $=$ total body weight LBM; total body fat $\%=($ total body fat $\times 100) /$ total body weight; (iii) fat-free mass $(\mathrm{FFM})=$ $16.28+0.4 \mathrm{E}$.

\section{Oxidative stress and antioxidant status}

The animals were killed on postnatal day 180 and livers were dissected out immediately, washed thoroughly with ice-cold saline, frozen in liquid nitrogen and stored at $-80^{\circ} \mathrm{C}$ until analysis.

A part of the liver was weighed, minced and homogenized $(10 \% \mathrm{w} / \mathrm{v})$ in $50 \mathrm{mM}$ phosphate buffer $(\mathrm{pH}$ 7.0). The homogenate was centrifuged at $1000 \mathrm{~g}$ for $20 \mathrm{~min}$ at $4^{\circ} \mathrm{C}$. A part of the supernatant was used for estimation of lipid peroxidation and protein carbonyls. The remaining supernatant was further centrifuged at $12000 \boldsymbol{g}$ for $20 \mathrm{~min}$ at $4^{\circ} \mathrm{C}$ to obtain the post-mitochondrial supernatant, which was used for the estimation of reduced glutathione (GSH) and activities of the antioxidant enzymes: catalase, superoxide dismutase (SOD) and glutathione peroxidase (GPx).

Lipid peroxidation was measured by the thiobarbituric acid color reaction for malondialdehyde (MDA) (28). Protein carbonyl content was measured spectrophotometrically using 2,4-dinitrophenyl-hydrazine (29). GSH was determined by its reaction with $o$-phthalaldehyde (30). Total SOD activity was assayed by monitoring the rate of inhibition of pyrogallol reduction (31). One unit of SOD represents the amount of enzyme required for $50 \%$ inhibition of pyrogallol reduction/ min. Catalase activity was assayed by monitoring the disappearance of $\mathrm{H}_{2} \mathrm{O}_{2}$ at $240 \mathrm{~nm}$ (32). One unit of catalase represents the decrease of $1 \mu \mathrm{mol} \mathrm{H}_{2} \mathrm{O}_{2} / \mathrm{min}$. The activity of total GPx was assayed using cumene hydroperoxide and GSH as substrates (33). One unit of GPx was defined as $\mu \mathrm{mol}$ NADPH oxidized $/ \mathrm{min}$. The protein content was determined using the modified Lowry method (34).

\section{Statistical analysis}

For maternal and neonatal data, differences between the control and restricted groups were analyzed using Student's $t$-test. Data collected from the offspring after weaning were analyzed using one-way ANOVA followed by the multiple range test/least significance difference (LSD) method. Wherever heterogeneity of variance was observed, differences between groups were tested by non-parametric Mann-Whitney U tests. Comparisons considered were: control (MC) vs MR, MR vs MSP and MR vs MSW. All values are presented as means \pm S.E. The differences were considered significant if $P$ was at least $<0.05$.

\section{Results}

\section{Parameters in mothers}

Maternal growth, mineral status and glucose homeostasis At the end of 3 months of feeding there was no significant difference in the body weight gain between the control and the MR rats. However, hemoglobin concentrations were significantly lower $(P<0.001)$ in $\mathrm{MR}$ animals than in controls. In addition, food intake was not significantly different 
between the different groups throughout growth, pregnancy and lactation.

There was, however, a significant decrease in the concentration of iron $(P<0.001)$, zinc $(P<0.001)$, magnesium $(P<0.001)$ and calcium $(P<0.05)$ in MR animals compared with controls after 12 weeks of feeding. There was no significant difference in copper concentrations (Table 1).

There were no significant differences between the two groups of mothers in the concentrations of fasting glucose and insulin, glucose AUC during an OGTT, HOMA index, and total cholesterol and triacylglycerols (Table 1).

Reproductive performance of dams Conception was $100 \%$ in both control and the MR groups. Weight gain during pregnancy was not significantly different between control and MR dams. Although the abortion rate was $14 \%(2 / 14)$ in MR animals (compared with none in controls), there were no significant differences between the groups in litter size $(5-11)$, percent of still births $(3-4 \%)$ and percent of deaths during lactation $(4-5 \%)$. However, the mean birth weight of pups was significantly lower in the MR group than in the controls (5.52 \pm 0.11 vs $6.08 \pm 0.14 \mathrm{~g} ; P<0.01)$.

\section{Parameters in offspring}

Growth characteristics of the offspring The offspring of the MR dams which had a lower birth weight continued to weigh less until postnatal day 180, whether they were kept on an MR diet or shifted to the control diet from parturition or weaning (Fig. 2). Although there were no differences in BMI among the different groups measured at postnatal day 100, the offspring of MR, MSP and MSW dams had a lower BMI compared with controls at postnatal

Table 1 Diet intake, physical and biochemical parameters in WNIN female rats fed control and MR diets for 12 weeks from weaning. Values are means \pm s.E. $(n=6)$.

\begin{tabular}{|c|c|c|}
\hline Parameter & Control group & MR group \\
\hline Food intake (g/day) & $11 \pm 0.38$ & $10.4 \pm 0.25$ \\
\hline Body weight gain (g) & $158 \pm 2.80$ & $158 \pm 4.34$ \\
\hline Hemoglobin $(g / d l)$ & $13.7 \pm 0.14$ & $10.7 \pm 0.37^{\star \star *}$ \\
\hline Fasting glucose (mmol/l) & $3.91 \pm 0.13$ & $4.11 \pm 0.17$ \\
\hline Fasting insulin (pmol/l) & $384 \pm 42.6$ & $444 \pm 42.9$ \\
\hline HOMA-IR & $11.1 \pm 1.04$ & $13.6 \pm 1.61$ \\
\hline $\begin{array}{l}\text { Glucose AUC } \\
(\mathrm{mmol} / \mathrm{l} \text { per } \mathrm{h})\end{array}$ & $10.9 \pm 0.66$ & $10.6 \pm 0.42$ \\
\hline Total cholesterol (mmol/l) & $1.55 \pm 0.10$ & $1.78 \pm 0.17$ \\
\hline Triglycerides $(\mathrm{mmol} / \mathrm{l})$ & $0.45 \pm 0.06$ & $0.49 \pm 0.05$ \\
\hline Iron $(\mu \mathrm{g} / \mathrm{ml})$ & $4.57 \pm 0.30$ & $3.19 \pm 0.12^{\star \star *}$ \\
\hline Copper $(\mu \mathrm{g} / \mathrm{ml})$ & $1.53 \pm 0.06$ & $1.59 \pm 0.09$ \\
\hline Zinc $(\mu \mathrm{g} / \mathrm{ml})$ & $1.54 \pm 0.04$ & $1.29 \pm 0.04^{\star \star *}$ \\
\hline Magnesium ( $\mu \mathrm{g} / \mathrm{ml})$ & $24.4 \pm 0.48$ & $17.8 \pm 0.52^{\star \star *}$ \\
\hline Calcium $(\mu \mathrm{g} / \mathrm{ml})$ & $188 \pm 17.56$ & $148 \pm 10.11^{*}$ \\
\hline
\end{tabular}

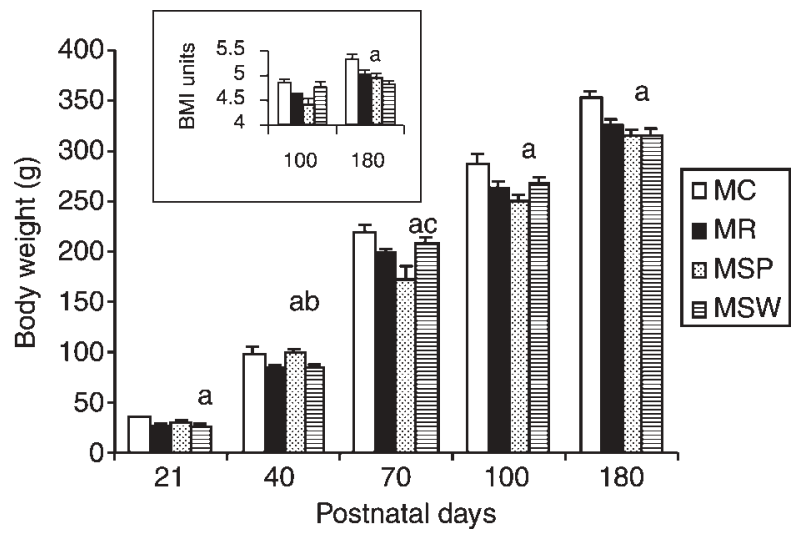

Figure 2 Body weights of different groups (MC, MR, MSP and MSW) at weaning and on postnatal days 40,70, 100 and 180 . Inset: BMI on postnatal days 100 and 180 . Values are means \pm S.E. $(n=6)$. ${ }^{a} \mathrm{MC}$ vs MR, ${ }^{\mathrm{b}} \mathrm{MSP}$ vs MR and ${ }^{\mathrm{C}} \mathrm{MSW}$ vs MR, significant at $P<0.05$ by ANOVA/multiple range test/LSD.

day 180 (Fig. 2). Although there were no differences in their diet intake, the haemoglobin concentrations of MR pups continued to be lower than those of controls until postnatal day 180 and rehabilitation either from parturition or weaning completely corrected these changes (data not shown).

Glucose tolerance and insulin resistance There were no significant differences in the fasting glucose concentrations between MC and MR, or MSP and MSW vs MR on days 40 and 70 of postnatal life. However, on postnatal days 100 and 180, the offspring of the MSP and MSW groups had significantly lower fasting glucose concentrations $(P<0.05)$ compared with controls (Fig. 3A). There was, however, no significant differences in fasting insulin concentrations among the four groups at any of the time-points tested (Fig. 3B). The AUC for glucose and insulin during an OGTT were, in general, not significantly different among the four groups at any time-point tested (Fig. 4A and B), except for some transient changes seen in the MSP and MSW groups on postnatal days 40 and 180 in glucose AUC values. It was indeed interesting that none of the animals in any of the groups had impaired OGT at any of the time-points tested.

Nevertheless, insulin resistance status was assessed among the offspring of the control and the other groups by computing indices, such as HOMA, based on fasting glucose and insulin or the ratio of the glucose AUC/insulin AUC which take into account values during OGTT. In general, MR pups were not significantly different from controls in both the indices tested at any of the four time-points tested (Figs 3C and 4C), nor did rehabilitation from parturition (MSP) or weaning (MSW) have any impact on these indices.

Body composition of the pups Interestingly, maternal MR had a significant effect on the body composition of 


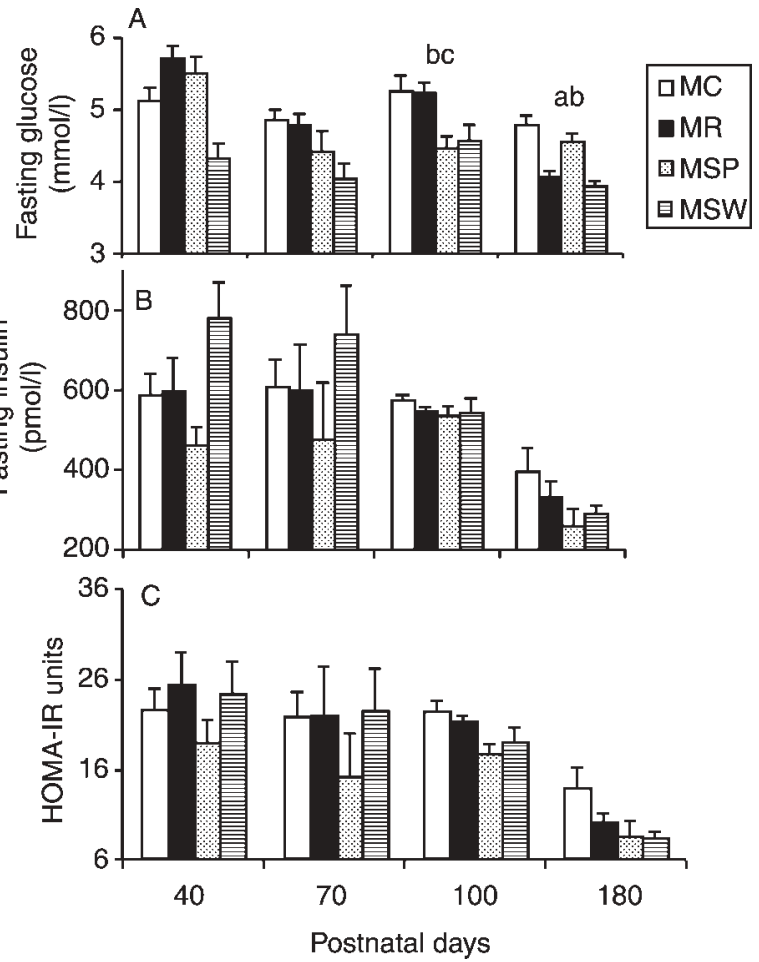

Figure 3 Fasting (A) glucose, (B) insulin and (C) HOMA-IR of the rat offspring of different groups on different postnatal days. Values are means \pm S.E. $(n=6) .{ }^{\mathrm{a}} \mathrm{MC}$ vs MR, ${ }^{\mathrm{b}} \mathrm{MSP}$ vs MR and ${ }^{\mathrm{C}} \mathrm{MSW}$ vs MR, significant at $P<0.05$ by ANOVA/multiple range test/LSD.

offspring measured on postnatal days 100 and 180 . Indeed, body fat \% was significantly higher $(P<0.01)$ in MR offspring compared with controls (Fig. 5A). Other markers of adipogenesis such as LBM and FFM (Fig. 5B and $C$ ) were significantly lower $(P<0.001)$ in the MR offspring compared with controls. However, rehabilitation of MR dams from parturition (MSP) or weaning MR pups onto the control diet (MSW) seemed to have no significant effect on any of these parameters at both the time-points tested.

Plasma lipids In keeping with high body fat \%, plasma triacylglycerol concentrations were significantly higher in the MR offspring than controls (Fig. 6) $(P<0.05)$ at all the four time-points tested. Interestingly, mineral rehabilitation from parturition (MSP) or weaning (MSW) appeared to correct the changes almost completely. Plasma total cholesterol and HDL cholesterol were, in general, not significantly different among the groups at any of the time-points tested (data not shown).

Oxidative stress and antioxidant status Chronic maternal MR resulted in a significant $(P<0.05)$ decrease in reduced GSH concentrations in the MR offspring and an increase in the concentrations of protein carbonyls (Table 2), albeit not statistically significant. Interestingly, rehabilitation from parturition or weaning could not prevent either the decrease in GSH or
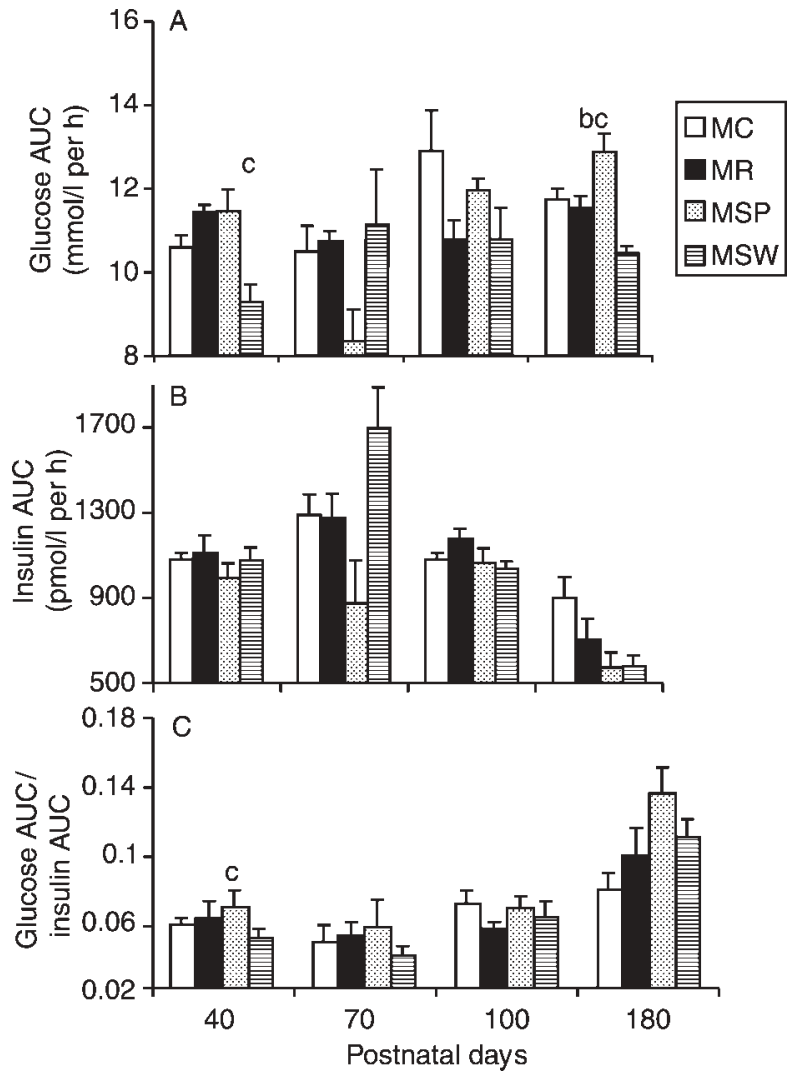

Figure 4 AUC of $(A)$ glucose, $(B)$ insulin and $(C)$ the ratio of glucose AUC to insulin AUC during the OGTT in the offspring on different postnatal days. Values are means \pm S.E. $(n=6)$. ${ }^{\mathrm{a}} \mathrm{MC}$ vs MR, ${ }^{\mathrm{b}} \mathrm{MSP}$ vs MR and ${ }^{\mathrm{c}} \mathrm{MSW}$ vs MR, significant at $P<0.05$ by ANOVA/multiple range test/LSD.

the increase in the concentrations of protein carbonyls. Lipid peroxides (MDA) and activities of the antioxidant enzymes catalase, SOD and GPx were similar among all the groups (Table 2).

\section{Discussion}

The present study was designed to assess the hypothesis that $50 \%$ restriction of maternal dietary minerals per se predisposes the offspring to insulin resistance in later life. We have assessed the effect of maternal MR during the phases of growth, pregnancy and lactation, on glucose homeostasis, insulin resistance and fat metabolism/adipogenesis in the offspring at 40, 70, 100 and 180 days of age. The results revealed that although 50\% maternal MR per se did not affect glucose homeostasis and insulin resistance in the offspring until postnatal day 180, it significantly increased their body fat content and concentrations of plasma triacylglycerols compared with controls. Further, these changes could be due to increased oxidative stress and/or decreased antioxidant defence in these offspring. It was interesting that neither rehabilitation of the MR 

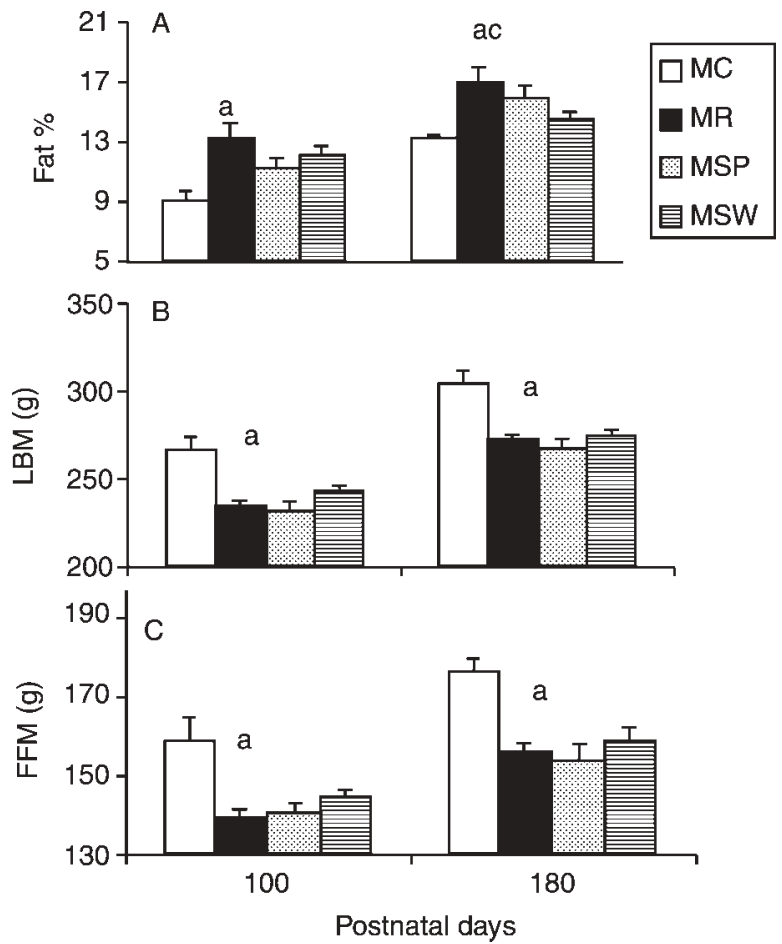

Figure 5 (A) Body fat \%, (B) LBM and (C) FFM of the offspring on postnatal days 100 and 180 as determined by TOBEC. Values are means \pm S.E. $(n=6) .{ }^{\mathrm{a}} \mathrm{MC}$ vs MR and ${ }^{\mathrm{C}} \mathrm{MSW}$ vs MR, significant at $P<0.05$ by ANOVA/multiple range test/LSD.

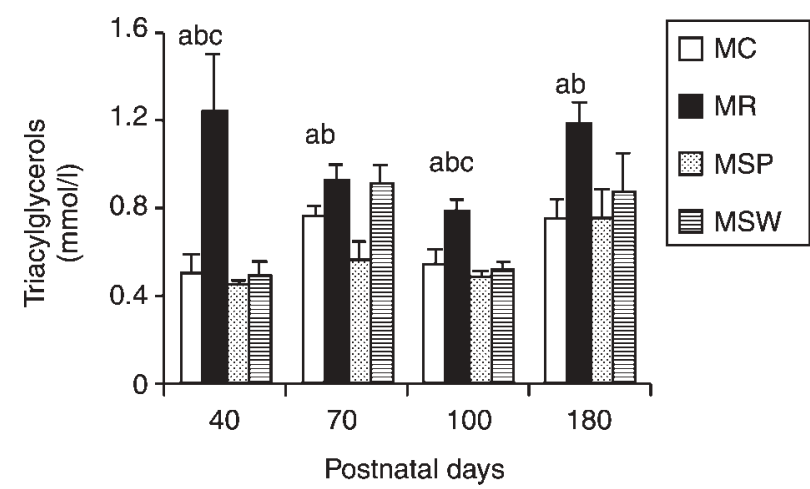

Figure 6 Plasma triacylglycerols in the offspring of different groups on postnatal days $40,70,100$ and 180 . Values are means \pm S.E. $(n=6) .{ }^{a} \mathrm{MC}$ vs MR, ${ }^{\mathrm{b}} \mathrm{MSP}$ vs MR and ${ }^{\mathrm{C}} \mathrm{MSW}$ vs MR, significant at $P<0.05$ by ANOVA/multiple range test/LSD. mothers from parturition nor weaning the MR pups onto the control diet had any beneficial effect in mitigating these changes.

There are a number of similarities between our results and the long-term effects reported in the offspring of mothers fed low protein diets (35-37). Both the models induced early growth retardation, and altered body composition and lipid profile. Shifting them to control diets from parturition or weaning appeared to have no significant effect on body weights.

Maternal MR in general had no significant effect on fasting glucose and insulin values until postnatal day 70. However, on postnatal days 100 and 180, MR, MSP and MSW offspring had significantly lower values for fasting glucose but not insulin, compared with controls. Although the HOMA-IR values computed based on fasting glucose and insulin were not statistically different among the groups, MR, MSP and MSW offspring had lower values compared with controls.

In keeping with the observations made above, there were no differences among the offspring of different groups in their OGT until postnatal day 70 and this was true even on postnatal day 100 . However, on postnatal day 180, the MSP offspring had the highest glucose AUC while the MC, MR and MSW pups were comparable. MR, MSP and MSW offspring, having a lower insulin AUC at this time-point compared with controls (of which only MSP and MSW were significant), probably indicates that maternal MR decreased the capacity of the offspring to respond to a challenge of oral glucose, and rehabilitation from parturition or weaning may not mitigate the defect. These observations are comparable with the previous reports on maternal protein and calorie malnutrition $(37,38)$. As a consequence of this, the ratio of glucose AUC to that of insulin was the highest in MSP offspring while that of MR and MSW was higher than that of MC, but not significant. These results based on OGT not only corroborate those from fasting concentrations of glucose and insulin, but also appeared to suggest that rehabilitation of MR mothers from parturition may worsen the insulin response of the offspring to a glucose challenge.

Despite the changes observed above, it was interesting to note that none of the offspring in any of the groups had impaired glucose tolerance until postnatal

Table 2 Indices of oxidative stress, antioxidants and antioxidant enzymes in liver homogenate of offspring of different groups on postnatal day 180. Values are means \pm S.E. $(n=6)$.

\begin{tabular}{lccccc}
\hline & $\begin{array}{c}\text { MDA } \\
\text { (nmol/mg protein) }\end{array}$ & $\begin{array}{c}\text { Protein carbonyls } \\
\text { (nmol/mg protein) }\end{array}$ & $\begin{array}{c}\text { Reduced GSH } \\
(\mu \mathrm{mol} / \mathrm{mg} \text { protein) }\end{array}$ & $\begin{array}{c}\text { Catalase } \\
\text { (units/mg protein) }\end{array}$ & $\begin{array}{c}\text { SOD } \\
\text { (units/mg protein) }\end{array}$ \\
(units/mg protein)
\end{tabular}

${ }^{\mathrm{a}} \mathrm{MC}$ vs MR, significant at $P<0.05$ by ANOVA/multiple range test. 
day 180. This may indicate the need for a greater duration of feeding for impaired glucose tolerance or insulin resistance to be manifest in the offspring. In this respect, our results are in partial agreement with those of Langley et al. (37) who showed that maternal protein restriction did not affect the glucose tolerance in the offspring at 3 months of age, but impaired it only at 15 months of age, at which time they were indeed diabetic. Our results are also in line with those of Lewis et al. (18) who demonstrated, in the offspring of iron-restricted rat dams, increased hypertension and altered serum lipids at 3 months of age but not impaired glucose tolerance.

In the present study, although maternal MR had no effect on glucose metabolism in the offspring, significant increases were observed in plasma triacylglycerols and body fat $\%$. Indeed, body fat $\%$ as computed by the TOBEC measurements is well validated and is an indicator of visible fat. The finding in our study that both LBM (which includes tissue-associated fat) and FFM showed a significant decrease in MR compared with MC appears to suggest that tissue-associated fat may be decreased in MR rats, whereas visible fat percent increased. These changes in body fat $\%$ are in agreement with those found by Lucas et al. (35) who observed altered lipid metabolism in the offspring of rat dams subjected to protein malnutrition during pregnancy.

The high body fat \% along with low body weight in the MR offspring observed here appear to be similar to those reported in the 'thin fat babies' seen in developing countries such as India, an abnormal condition attributed to maternal malnutrition (39). Though it is not immediately clear how maternal mineral restriction altered lipid metabolism, it appears that it may not be due to the increased oxidative stress in these animals. To the best of our knowledge, this is the first report showing that chronic maternal MR per se during the phases of growth, pregnancy and lactation affected lipid metabolism and antioxidant status in the offspring.

There is abundant material in the literature that indicates that altered adipogenesis/lipid metabolism is the earliest change seen much before tissue insulin resistance manifests (40-43). Indeed, insulin resistance is hypothesized to originate in impaired adipogenesis/lipid metabolism (42-44). However, in our study, MR offspring had neither impaired glucose tolerance nor insulin resistance until postnatal day 180 , although they had high body fat content and altered lipid metabolism. Further, it was somewhat perplexing that the rehabilitation of MR dams from parturition or weaning MR pups onto the control diet almost completely reversed the plasma triacylglycerol concentrations, but had little effect on the body fat \%, LBM and FFM, indicating only partial reversibility of the changes. Thus, maternal MR per se had no discernible effect on glucose tolerance or insulin resistance in the offspring, although it altered the body fat composition and lipid metabolism.
Nevertheless, in view of the earlier reports in the literature that changes in adipogenesis/fat metabolism are the earliest events in the manifestation of insulin resistance, our observations are not necessarily in conflict with the hypothesis that maternal MR per se may predispose the offspring to insulin resistance in later life.

\section{Acknowledgements}

The authors thank Dr Kamala Krishnaswamy, former Director, National Institute of Nutrition (ICMR), Hyderabad and Dr B Sivakumar, officer in charge, National Institute of Nutrition, for their interest and help during the course of these investigations. $\mathrm{L} \mathrm{V}$ is grateful to the Council for Scientific and Industrial Research, India for a Junior Research Fellowship.

\section{References}

1 Ariyuki F. Growth retardation induced in rat fetuses by maternal fasting and massive doses of ergocalciferol. Journal of Nutrition $1987117342-348$.

2 Metcoff J, Costiloe JP, Crosby W, Bentle L, Seshachalam D, Sandstead HH, Bodwell CE, Weaver F \& McClain P. Maternal nutrition and fetal outcome. American Journal of Clinical Nutrition 198134 (Suppl 4) 708-721.

3 Wilkin TJ, Metcalf BS, Murphy MJ, Kirkby J, Jeffery AN \& Voss LD. The relative contributions of birth weight, weight change, and current weight to insulin resistance in contemporary 5-yearolds: the Early Bird Study. Diabetes 200251 3468-3472.

4 Barker DJ, Hales CN, Fall CH, Osmond C, Phipps K \& Clark PM. Type 2 (non-insulin-dependent) diabetes mellitus, hypertension and hyperlipidaemia (syndrome $\mathrm{X}$ ): relation to reduced fetal growth. Diabetologia $19933662-67$.

5 Singhal A, Wells J, Cole TJ, Fewtrell M \& Lucas A. Programming of lean body mass: a link between birth weight, obesity and cardiovascular disease? American Journal of Clinical Nutrition $2003 \mathbf{7 7}$ 726-730.

6 Haffner SM, Valdez RA, Hazuda HP, Mitchell BD, Morales PA \& Stern MP. Prospective analysis of the insulin-resistance syndrome (syndrome X). Diabetes $1992 \mathbf{4 1} 715-722$.

7 Reaven GM. Banting lecture 1988. Role of insulin resistance in human disease. Diabetes 198837 1595-1607.

8 Barker DJ. Programming the baby. In Mothers, Babies and Disease in the Later Life, pp 14-36. Ed. DJ Barker. London: BMJ Publishing Group, 1994.

9 Godfrey KM \& Barker DJ. Fetal nutrition and adult disease. American Journal of Clinical Nutrition $2000 \mathbf{7 1}$ (Suppl 5) 1344 S-1352S

10 Simmons RA, Templeton LJ \& Gertz SJ. Intrauterine growth retardation leads to the development of type 2 diabetes in the rat. Diabetes $2001502279-2286$.

11 Boloker J, Gertz SJ \& Simmons RA. Gestational diabetes leads to the development of diabetes in adulthood in the rat. Diabetes 200251 1499-1506.

12 Woodall SM, Johnston BM, Breier BH \& Gluckman PD. Chronic maternal undernutrition in the rat leads to delayed postnatal growth and elevated blood pressure of offspring. Pediatric Research $199640438-443$.

13 Langley SC \& Jackson AA. Increased systolic blood pressure in adult rats induced by fetal exposure to maternal low protein diets. Clinical Science $199486217-222$.

14 Persson E \& Jansson T. Low birth weight is associated with elevated adult blood pressure in the chronically catheterized guinea pig. Acta Physiologica Scandinavica 1992145 195-196. 
15 Anderson RA. Role of dietary factors: micronutrients. Nutrition Reviews 200058 S10-S11.

16 Davis CM \& Vincent JB. Chromium oligopeptide activates insulin receptor tyrosine kinase activity. Biochemistry $1997 \quad 36$ $4382-4385$

17 Verma S, Cam MC \& McNeill JH. Nutritional factors that can favorably influence the glucose/insulin system: vanadium. Journal of American College of Nutrition 199817 11-18.

18 Lewis RM, Petry CJ, Ozanne SE \& Hales CN. Effects of maternal iron restriction in the rat on blood pressure, glucose tolerance and serum lipids in the 3-month-old offspring. Metabolism 2001 $50562-567$.

19 Van den Broek N. Anaemia in pregnancy in developing countries. British Journal of Obstetrics and Gynaecology 1998105 385-390.

20 Singla PN, Tyagi M, Kumar A, Dash D \& Shankar R. Fetal growth in maternal anaemia. Journal of Tropical Pediatrics $1997 \mathbf{4 3}$ 89-92.

21 UNICEF. The State of the World's Children 1998. Oxford and New York: Oxford University Press, 1998.

22 Reeves PG. Components of the AIN-93 diets as improvements in the AIN-76A diet. Journal of Nutrition 1997127 838S-841S.

23 Matthews JN, Altman DG, Campbell MJ \& Royston P. Analysis of serial measurements in medical research. British Medical Journal $199027230-235$.

24 Analytical Methods. In Instruction manual for Varian SpectrAA 220 Publication No. 85-100009-00, pp 89-92. Varian Australia Pty Ltt.: Mulgrave Victoria, 1999.

25 Bracco EF, Yang MU, Segal K, Hashim SA \& Van Itallie TB. A new method for estimation of body composition in the live rat. Proceedings of the Society for Experimental Biology and Medicine $1983 \mathbf{7 4}$ $143-146$.

26 Cunningham JJ, Molnar JA, Meara PA \& Bode HH. In vivo total body electrical conductivity following perturbations of body fluid compartments in rats. Metabolism $198635572-575$.

27 Morbach CA \& Brans YW. Determination of body composition in growing rats by total body electrical conductivity. Journal of Pediatric Gastroenterology and Nutrition 199214 283-292.

28 Balasubramanian KA, Manohar M \& Mathan VI. An unidentified inhibitor of lipid peroxidation in intestinal mucosa. Biochimica et Biophysica Acta $198896251-58$.

29 Uchida K, Kanematsu M, Sakai K, Matsuda T, Hattori N, Mizuno Y, Suzuki D, Miyata T, Noguchi N, Niki E \& Osawa T. Proteinbound acrolein: potential markers for oxidative stress. PNAS $1998954882-4887$

30 Hissin PJ \& Hilf R. A fluorometric method for determination of oxidized and reduced glutathione in tissues. Analytical Biochemistry $1976 \mathbf{7 4} 214-226$.

31 Marklund S \& Marklund G. Involvement of the superoxide anion radical in the autoxidation of pyrogallol and a convenient assay for superoxide dismutase. European Journal of Biochemistry 1974 $47469-474$

32 Aebi H. Catalase in vitro. Methods in Enzymology 1984105 $121-126$.

33 Paglia DE \& Valentine WN. Studies on the quantitative and qualitative characterization of erythrocyte glutathione peroxidase. Journal of Laboratory and Clinical Medicine 1967 70 158-169.

34 Schacterle GR \& Pollack RL. A simplified method for the quantitative assay of small amounts of protein in biologic material. Analytical Biochemistry 197351 654-655.

35 Lucas A, Baker BA, Desai M \& Hales CN. Nutrition in pregnant or lactating rats programs lipid metabolism in the offspring. British Journal of Nutrition $1996 \mathbf{7 6} 605-612$.

36 Shepherd PR, Crowther NJ, Desai M, Hales CN \& Ozanne SE. Altered adipocyte properties in the offspring of protein malnourished rats. British Journal of Nutrition $1997 \mathbf{7 8} 121-129$.

37 Langley SC, Browne RF \& Jackson AA. Altered glucose tolerance in rats exposed to maternal low protein diets in utero. Comparative Biochemistry and Physiology 1994109 223-229.

38 Swenne I, Crace CJ \& Milner RD. Persistent impairment of insulin secretory response to glucose in adult rats after limited period of protein-calorie malnutrition early in life. Diabetes 198736 454-458.

39 Yajnik CS, Fall CH, Coyaji KJ, Hirve SS, Rao S, Barker DJ, Joglekar C \& Kellingray S. Neonatal anthropometry: the thin-fat Indian baby. The Pune Maternal Nutrition Study. International Journal of Obesity and Related Metabolic Disorders 200327 173-180.

40 Smith U. Impaired ('diabetic') insulin signaling and action occur in fat cells long before glucose intolerance - is insulin resistance initiated in the adipose tissue? International Journal of Obesity and Related Metabolic Disorders 200226 897-904.

41 Srinivasan SR, Myer L \& Berenson GS. Predictability of childhood adiposity and insulin for developing insulin resistance syndrome (Syndrome X) in young adulthood: the Bogalusa Heart Study. Diabetes 200251 204-209.

42 Yajnik CS. The lifecycle effects of nutrition and body size on adult adiposity, diabetes and cardiovascular disease. Obesity Reviews $20023217-224$.

43 Jones AP \& Friedman MI. Obesity and adipocyte abnormalities in offspring of rats undernourished during pregnancy. Science 1982 $191518-1519$

44 Smith U, Axelsen M, Carvalho E, Eliasson B, Jansson PA \& Wesslau C. Insulin signaling and action in fat cells: associations with insulin resistance and type 2 diabetes. Annals of the New York Academy of Science $1999 \mathbf{8 9 2} 119-126$.

Received 19 December 2003

Accepted 26 February 2004 